\title{
Unexpected Scholl Reaction of 6,7,13,14- Tetraarylbenzo[k]tetraphene: Selective Formation of Five-Membered Rings in Polycyclic Aromatic Hydrocarbons
}

Junzhi Liu, ${ }^{\dagger}$ Akimitsu Narita, ${ }^{\dagger}$ Silvio Osella, ${ }^{\dagger}$ Wen Zhang, $^{\dagger}$ Dieter Schollmeyer, ${ }^{\#}$ David Beljonne, ${ }^{\ddagger}$ Xinliang Feng, ${ }^{*} \S$ and Klaus Müllen ${ }^{*} \dagger$

${ }^{\dagger}$ Max-Planck Institut für Polymerforschung, Ackermannweg 10, 55128 Mainz, Germany

${ }^{\ddagger}$ Laboratory for Chemistry of Novel Materials, University of Mons, Place du Parc 20, B-7000 Mons, Belgium

\# Institut für Organische Chemie, Universität Mainz, Düsbergweg 10-14, 55099 Mainz, Germany

${ }^{\S}$ Center for Advancing Electronics Dresden (CFAED) \& Department of Chemistry and Food Chemistry, Technische Universität Dresden, 01062 Dresden, Germany

Supporting Information

ABSTRACT: Cyclodehydrogenation is a versatile reaction that has enabled the syntheses of numerous polycyclic aromatic hydrocarbons (PAHs). We now describe a unique Scholl reaction of 6,7,13,14-tetraarylbenzo[ $k]$ tetraphene, which "unexpectedly" forms five-membered rings accompanying highly selective 1,2-shift of aryl groups. The geometric and optoelectronic nature of the resulting bistetracene analogue with five-membered rings is comprehensively investigated by single-crystal X-ray, NMR, UV-vis absorption, and cyclic voltammetry analyses. Furthermore, a possible mechanism is proposed to account for the selective five-membered-ring formation with the rearrangement of the aryl groups, which can be rationalized by density functional theory (DFT) calculations. The theoretical results suggest that the formation of the bistetracene analogue with five-membered rings is kinetically controlled while an "expected" product with six-membered rings is thermodynamically more favored. These experimental and theoretical results provide further insights into the still controversial mechanism of the Scholl reaction as well as open up an unprecedented entry to extend the variety of PAHs by programing otherwise unpredictable rearrangements during the Scholl reaction.

\section{INTRODUCTION}

The Scholl reaction, an oxidative cyclodehydrogenation, has been extensively used for the synthesis of polycyclic aromatic hydrocarbons (PAHs) ${ }^{1-4}$ since the pioneering work by Scholl in 1910.5, Especially after the facile, mild, and high-yield synthesis of hexa-peri-hexabenzocoronene (HBC) from hexaphenylbenzene, ${ }^{7-9}$ a number of larger PAHs have been prepared via this protocol, including a hexagonal disk with 222 $\mathrm{sp}^{2}$ carbons as the largest example to date. ${ }^{10,11}$ More recently, the high potential of the Scholl reaction was further demonstrated through the syntheses of long graphene nanoribbons extending over $600 \mathrm{~nm}^{12}$ as well as PAHs with seven- ${ }^{13,14}$ and eight-membered rings, ${ }^{15,16}$ such as warped nanographene involving five seven-membered rings and tetrabenzo[8]circulene, respectively. However, the Scholl reaction sometimes "fails" due to migration of alkyl and aryl groups as well as skeletal rearrangements, ${ }^{17-23}$ yielding unexpected and often undesired and/or undefined PAH structures. Furthermore, the Scholl reaction sometimes prefers formation of a five-membered ring rather than a six-membered ring, while the reason for such selectivity remains unclear. ${ }^{24-29}$
A deeper understanding and better control of the Scholl reaction are therefore mandatory to further develop the chemistry of PAHs and nanographenes.

Great efforts have been dedicated to synthesize oligoacene systems, which possess attractive properties, including low optical gap, high charge-carrier mobility, singlet fission, as well as open-shell features in the ground state. ${ }^{30-34}$ Moreover, we have recently reported the synthesis and characterization of tetrabenzo[ $[a, f, j, o]$ perylene, i.e., bistetracene (Scheme 1), which demonstrated intriguing properties, especially a small optical energy gap of ca. $1.56 \mathrm{eV}$ and an open-shell ground-state biradical character. ${ }^{35}$ However, the bistetracene turned out to be highly unstable under ambient conditions, undergoing oxidation to the corresponding diketone, tetrabenzo $[a, f, j, o]$ perylene-9,19-dione. Such instability is a common problem also for higher acenes, which hinders further investigations and applications of the acene-based compounds. To circumvent this stability issue, one avenue explores acene-like compounds

Received: October 5, 2015

Published: February 9, 2016 
Scheme 1. Oxidation of Bistetracene to a Diketone under Ambient Conditions

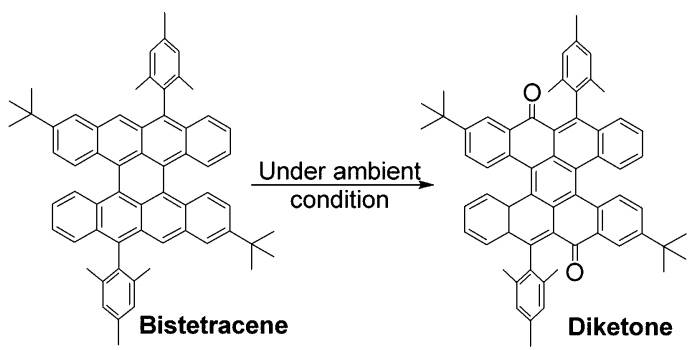

containing five membered rings rather than the traditional acenes solely consisting of six-membered rings. ${ }^{36,37}$

During our attempts to synthesize tetrabenzo[ $[a, c d, j, l m]$ perylene (5) through the Scholl reaction of 6,7,13,14tetraarylbenzo[ $k]$ tetraphene (1a) (Scheme 2), we "unexpect-

Scheme 2. Cyclodehydrogenation of 6,7,13,14-

Tetraarylbenzo $[k]$ tetraphenes 1

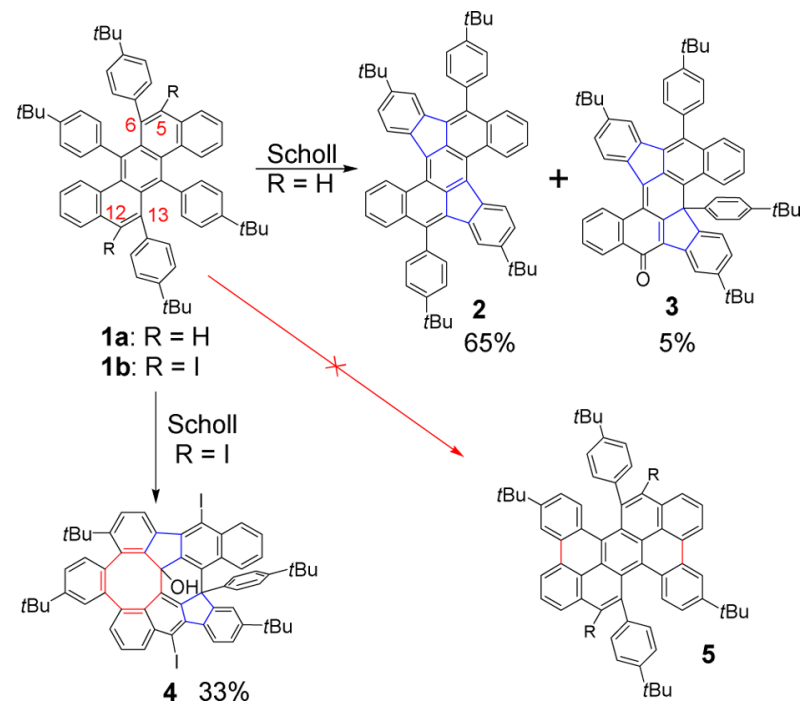

edly" discovered the formation of bistetracene analogue, 5,14diaryldibenzo $[a, m]$ rubicene (2), with two five-membered rings, which showed high stability and could be characterized by crystal structure analysis. Here, we report the experimental and theoretical studies on the Scholl reaction of the 6,7,13,14tetraarylbenzo $[k]$ tetraphene structures, which do not undergo the usual six-membered-ring formation.

\section{RESULTS AND DISCUSSION}

Matrix-assisted laser desorption/ionization time-of-flight (MALDI-TOF) mass spectrometry (MS), NMR, and singlecrystal X-ray analyses undoubtedly demonstrate the formation of an unprecedented bistetracene analogue $\mathbf{2}$ as the major product, rather than its isomer $\mathbf{5}$. To our astonishment, the aryl groups at the 6 and 13 positions of 1a did not hinder the fivemembered ring formation, but were selectively rearranged to the neighboring positions. This course of the reaction could be understood by calculating the thermodynamic stabilization energies of the intermediate structures. We could also isolate and unambiguously characterize $(R)-9 b, 14$-diaryldibenzo[ $[a, m]$ rubicen-5 $(9 b H)$-one (3) as a byproduct, which could provide a further understanding for the reaction mechanism of the Scholl reaction. Moreover, when the 5 and 12 positions of 1 a were blocked with iodo substituents (1b), hindering the 1,2-shift of the aryl groups, the Scholl reaction induced rearrangement of another aryl group to provide $(12 b R, 12 c 2 R)-8,17$-diiodo- $12 b$ (4-tert-butylphenyl)benzo[5,6]indeno[1,2,3,4-vwxa] -uoreno$[9,1,2,3-c d e f]$ tetraphenylen-12c2 $(12 b H)$-ol (4) with an eightmembered ring. These experimental and theoretical results provide a new mechanistic insight into the Scholl reaction and give access to unprecedented PAHs by controlling otherwise "unexpected" rearrangements.

The 6,7,13,14-tetraarylbenzo[ $k]$ tetraphene precursors 1a and 1b were synthesized as depicted in Scheme 3. First, selective Suzuki coupling of 1,4-dibromo-2,5-diiodobenzene (6) and [4(tert-butyl)phenyl] boronic acid gave $2^{\prime}, 5^{\prime}$-dibromo-4,4" $4^{\prime \prime}$ di-tertbutyl-1,1': $1^{\prime}, 1^{\prime \prime}$-terphenyl (7) in $72 \%$ yield. [2-(4-tertButylphenylethynyl)phenyl]boronic acid (10) was obtained through Sonogashira coupling of 1-bromo-2-iodobenzene (8) and 4-tert-butylphenylacetylene, followed by borylation. Then $4^{\prime \prime}$-(tert-butyl)-5' -(4-tert-butylphenyl)-2-(4-tert-butylphenylethynyl)-4'-[2-(4-tert-butylphenylethynyl)phenyl]-1, $1^{\prime}: 2^{\prime}, 1^{\prime \prime}$-terphenyl (11) was prepared by 2 -fold Suzuki coupling of 7 with 10 in $50 \%$ yield. ICl-induced cyclization was subsequently performed to provide 6,7,13,14-tetrakis(4-tert-butylphenyl)5,12-diiodobenzo[k]tetraphene (1b). Next, the iodo substituents were removed by using $n$-BuLi to afford $6,7,13,14$ tetrakis(4-tert-butylphenyl)benzo[ $k]$ tetraphene (1a). Precursors $\mathbf{1 a}$ and $\mathbf{1 b}$ were comprehensively characterized by MALDI-TOF MS and NMR spectroscopy. Furthermore, the molecular structure of $\mathbf{1 b}$ was proven by the single-crystal X-ray analysis (Figure S2). The Scholl reaction of precursor 1a was carried out with 2,3-dichloro-5,6-dicyano-1,4-benzoquinone (DDQ) and trifluoromethanesulfonic acid ( $\mathrm{TfOH})$ in dry dichloromethane (DCM) at $0{ }^{\circ} \mathrm{C}$, which afforded 2 as the major product, in $65 \%$ yield. Remarkably, two five-membered rings were formed upon the cyclodehydrogenation of 1a. This process implied the highly selective 1,2-shift of the tertbutylphenyl groups to the neighboring positions, although the formation of the usual six-membered rings (such as compound 5) appears to require much less strain.

Reddish-brown prism-shaped crystals of 2 suitable for single crystal X-ray analysis could be grown from solutions in hexane/ dichloromethane, elucidating the molecular structure as displayed in Figure 1. Notably, compound 2 has a nonplanar skeleton because of the internal steric repulsions, showing slightly twisted cores

with a mean torsional angle of $23.8^{\circ}$ (Figures 1c). More interestingly, the structural distortion makes 2 chiral, and the two enantiomers form a dimer packing by intermolecular $\pi-\pi$ interactions with an interlayer distance as short as $3.79 \AA$ (Figure $1 \mathrm{~b}$ ). The $\mathrm{C}-\mathrm{C}$ bonds at the five-membered rings of 2 (Figure 2a) are obviously longer (1.48-1.49 $\AA$ ) than other bonds $(1.36-1.47 \AA)$, which suggests their single bond nature. The Nucleus independent chemical shift (NICS) calculation at the GIAO-B3LYP/6-31G (d,p) level ${ }^{38,39}$ was carried out for compound 2 to investigate the aromaticity of each ring, revealing NICS values of $-17.34,-8.44,-20.06$, and -20.39 for the benzene rings, and 8.65 for the five-membered ring (Figure $2 \mathrm{~b}$ ). These results seem to indicate that the fivemembered rings of $\mathbf{2}$ are antiaromatic while its benzene rings are all aromatic.

Although the detailed mechanism of the Scholl reaction remains elusive, routes involving either radical cations (electron transfer) or arenium cations (proton transfer) have been put 
Scheme 3. Synthesis of PAHs 2, 3, and $4^{a}$

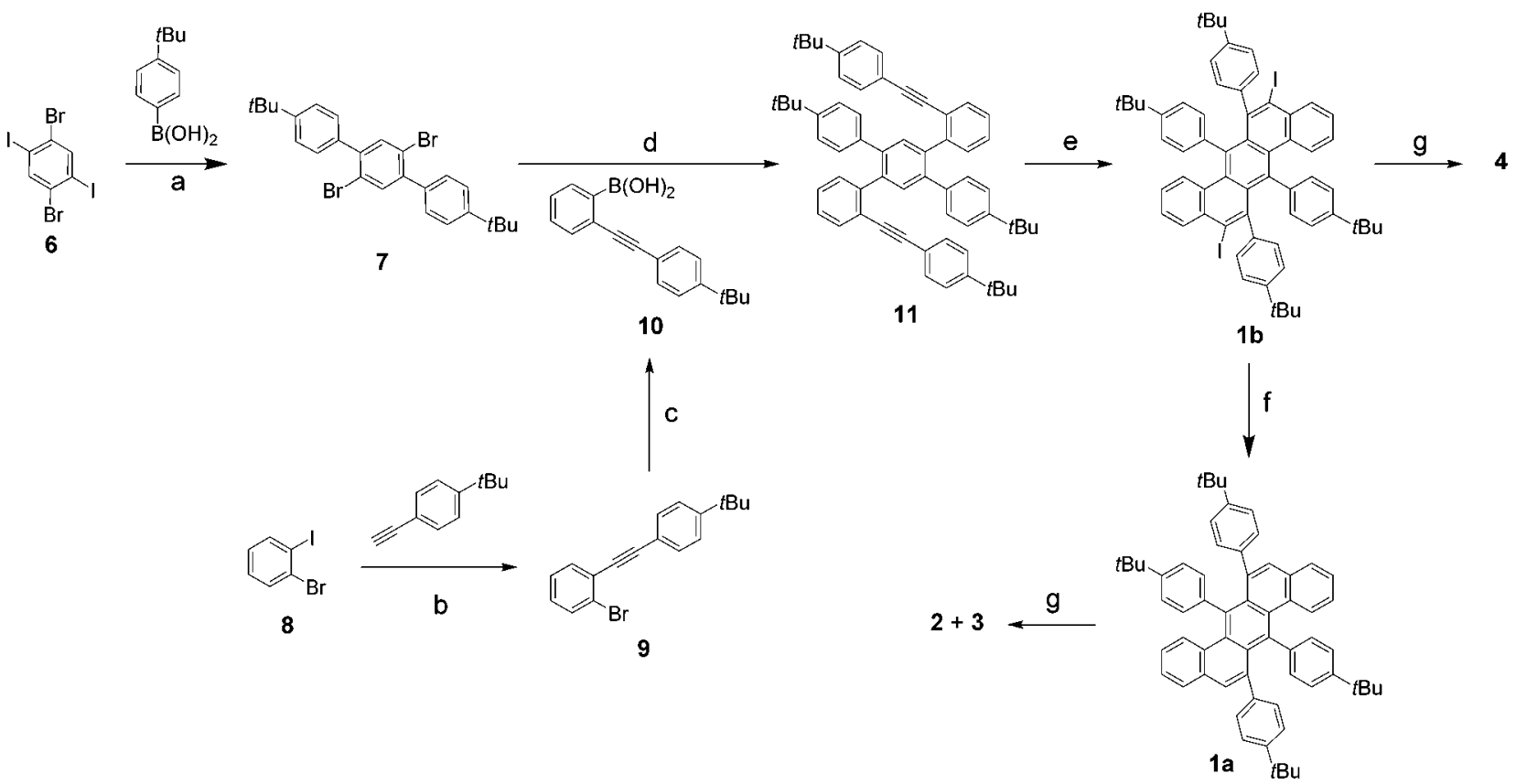

${ }^{a}$ Reagents and conditions: (a) $\mathrm{Pd}\left(\mathrm{PPh}_{3}\right)_{4}, \mathrm{~K}_{2} \mathrm{CO}_{3}$, dioxane $/ \mathrm{H}_{2} \mathrm{O}, 90{ }^{\circ} \mathrm{C}, 24 \mathrm{~h}, 72 \%$; (b) $\mathrm{PdCl}_{2}\left(\mathrm{PPh}_{3}\right)_{2}, \mathrm{CuI}, \mathrm{Et}{ }_{3} \mathrm{~N}, \mathrm{THF}, \mathrm{rt}, 92 \%$; (c) $n$-BuLi, THF, $\mathrm{B}(\mathrm{OiPr})_{3},-78{ }^{\circ} \mathrm{C}$ to rt; (d) $\mathrm{Pd}\left(\mathrm{PPh}_{3}\right)_{4}, \mathrm{~K}_{2} \mathrm{CO}_{3}$, dioxane $/ \mathrm{H}_{2} \mathrm{O}, 95{ }^{\circ} \mathrm{C}, 24 \mathrm{~h}, 50 \%$; (e) ICl $(1 \mathrm{M}$ in DCM $),-78{ }^{\circ} \mathrm{C}, 3 \mathrm{~h}, 85 \%$; (f) $n$-BuLi, $\mathrm{THF}$, $\mathrm{MeOH}, 1 \mathrm{~h}, 53 \%$; (g) $\mathrm{DDQ} / \mathrm{CF}_{3} \mathrm{SO}_{3} \mathrm{H}, \mathrm{DCM}, 0{ }^{\circ} \mathrm{C}, 1 \mathrm{~h}, 2: 65 \%, 3: 5 \%, 4: 33 \%$.

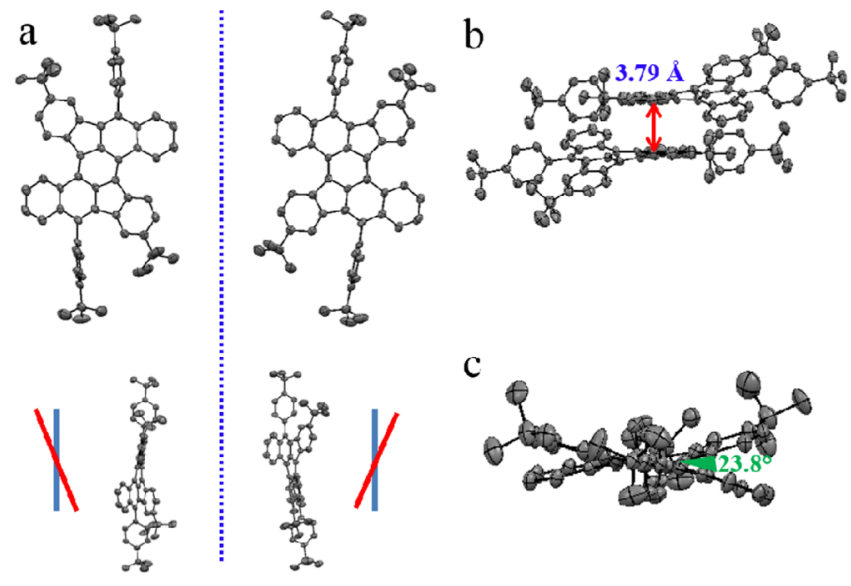

Figure 1. Crystal structure of 2. (a) Top and side views of the enantiomer pair. (b) Crystal packing of dimer from side view. (c) Torsional angle of $\mathbf{2}$.

forward..$^{29,40-43}$ In order to examine the plausibility of the proposed reaction mechanism as well as to better understand the formation of compound $\mathbf{2}$ with five-membered rings instead of the "expected" product 5, theoretical studies were carried out. All structures have been optimized at the DFT level of theory with the B3LYP functional ${ }^{44}$ and $6-31+G(d, p)$ Pople basis set, ${ }^{45}$ using the Gaussian 09 program package. ${ }^{46}$ Since the presence of the solvent turns out to have a high impact on the energetics, single point calculations have been carried out in DCM (dicholoromethane; more details in the SI) on the basis of the gas-phase optimized geometries. The zero energy reference point is taken as the precursor $1 \mathrm{a}+\mathrm{DDQ}(\mathrm{TfOH})$ for the radical cation (arenium cation) mechanism, in order to directly compare both rearrangement and electron transfer (protonation) steps. At first, it is worth pointing out that the
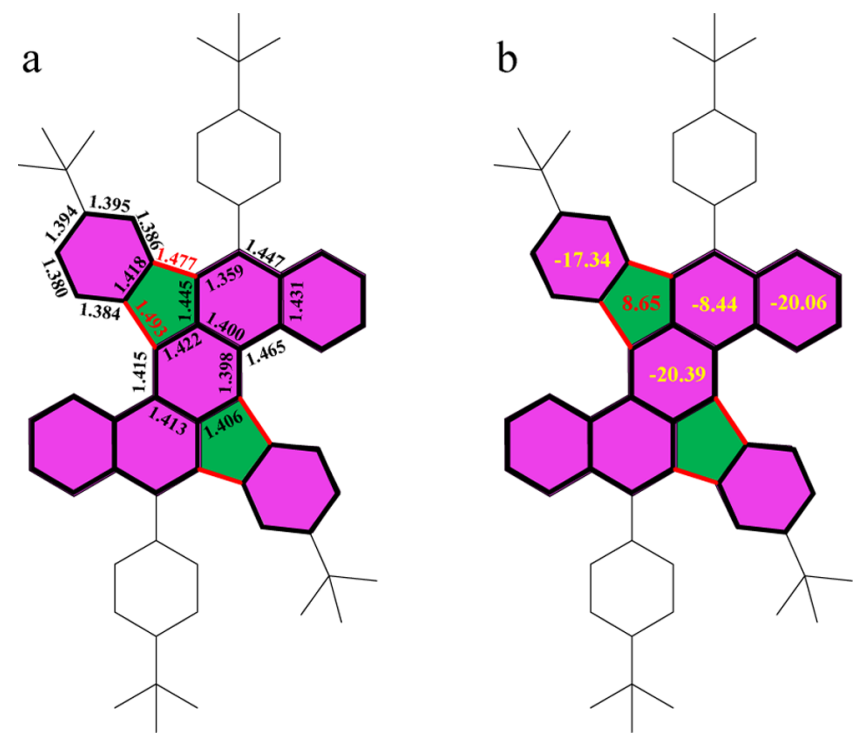

Figure 2. (a) Bond lengths of 2 from single crystal analysis. (b) NICS values from calculation at the GIAO-B3LYP/6-31G $(\mathrm{d}, \mathrm{p})$ level.

direct comparison of the energies of compounds $\mathbf{2}$ and $\mathbf{5}$ leads to a difference of $0.61 \mathrm{eV}$ in favor of $\mathbf{5}$ with six-membered rings. Hence, we anticipate that the preferred formation of compound $\mathbf{2}$ is kinetically controlled.

To ascertain the relative likelihood of the two proposed scenarios in the Scholl reaction, namely the arenium cation versus radical cation mechanism, we first focus on the 1,2-shift of the aryl group, which occurs prior to the $\mathrm{C}-\mathrm{C}$ bond formation. The rearrangement of the aryl groups can follow either the radical cation or the arenium cation protocols ${ }^{29,47}$ (Scheme 4). In particular, we compare the protonation of precursor 1 a to arenium cation 15 with the formation of radical 
Scheme 4. Comparison between Radical Cation and Arenium Cation Mechanisms for the 1,2-Shift of the Aryl Groups

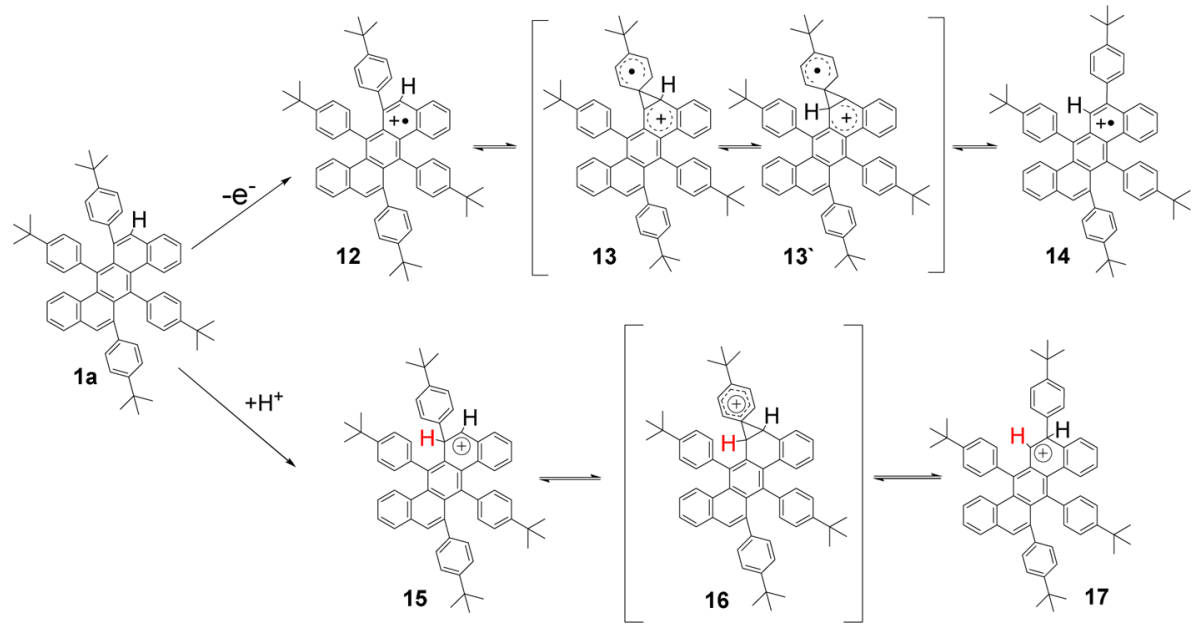

Scheme 5. Possible Pathways to Formation of a Five-Membered Ring from 14

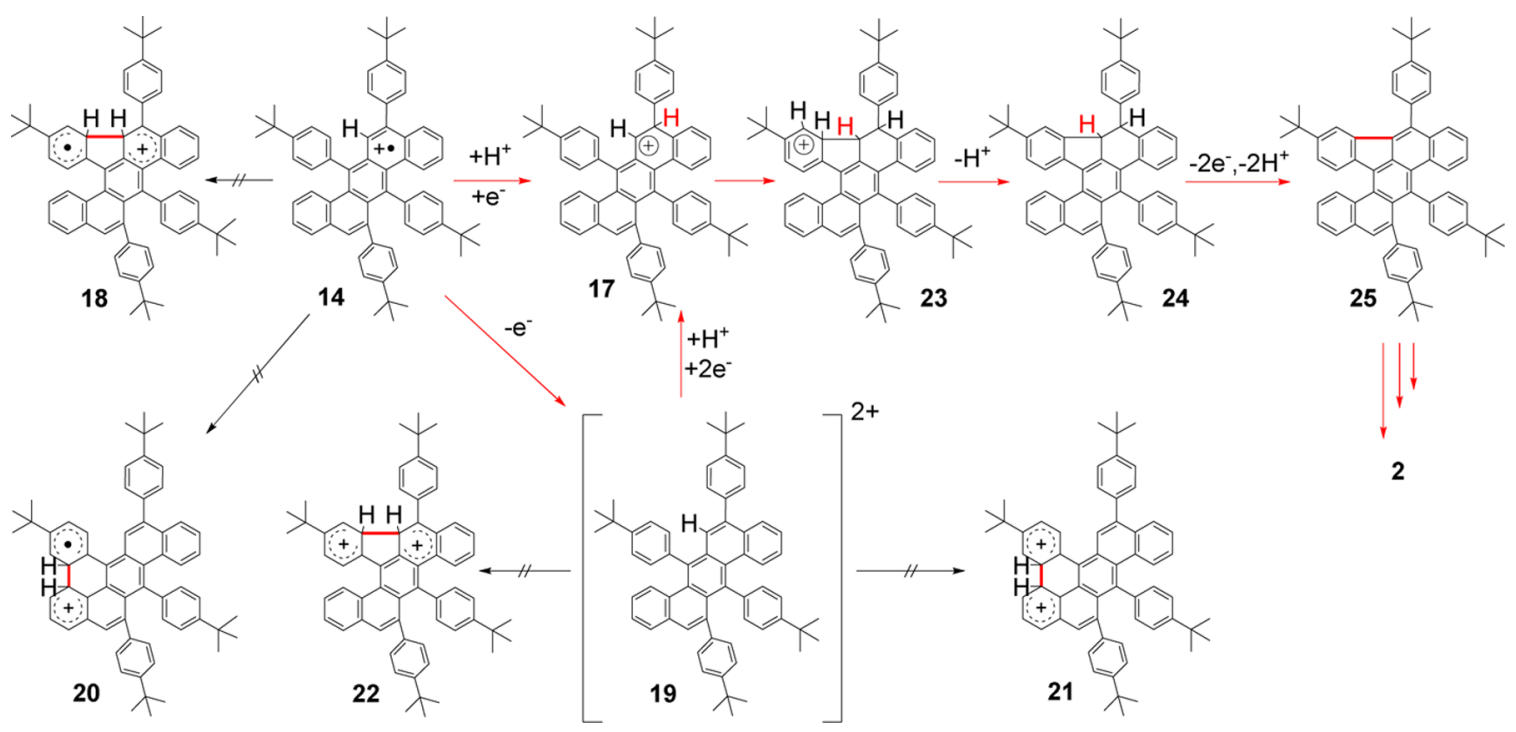

cation 12, as depicted in Scheme 4. Radical cation 12 and arenium cation 15 can both potentially undergo 1,2-shift of the 4-tert-butylphenyl group to afford radical cation 14 and arenium cation 17, respectively, via radical cations 13 and $13^{\prime}$ and arenium cation $\mathbf{1 6}$ as intermediate states with a threemembered ring (Scheme 4). The protonation energy of structure $15(1.09 \mathrm{eV})$ is close to the value computed by Johnson et al. ${ }^{29}$ in the case of phenylnaphtalene, as anticipated from the expected similar acidity of the two aromatic hydrocarbons. Very interestingly, a much smaller energy penalty (of $0.13 \mathrm{eV}$ ) is associated with the formation of structure 12 resulting from a radical cation mechanism. In view of such a large difference in stability between the two intermediate compounds, we can assume that the radical cation mechanism prevails over the arenium route as far as the aryl migration step is concerned. This is supported by the following control experiment: we treated 1a with $\mathrm{TfOH}$ in the absence of DDQ and did not observe the selective 1,2-shift, but rather the formation of an inseparable mixture of products that could not be characterized. Although the rearrangement of aryl groups is normally proposed to proceed through arenium cation intermediates in the literature, ${ }^{29}$ these theoretical and experimental results thus strongly suggest that it instead involves an electron-transfer mechanism in this specific case. The selective 1,2-shift of the aryl groups during the Scholl reaction was then investigated by comparing the relative stability of intermediate radical cation 12 and its isomer 14 . The DFT calculations indicate that $\mathbf{1 2}$ (energy of $0.13 \mathrm{eV}$ ) is less stable than $14(-0.17 \mathrm{eV})$ by $0.30 \mathrm{eV}$, a difference associated with steric hindrance. This result thus indicates that the 1,2-shift of the aryl group from position 6 to 5, induced by an electron transfer process, is exergonic. We note that, in the (unlikely) case where 15 (energy of $1.09 \mathrm{eV}$ ) would form along the arenium mechanism, its conversion to $17(+0.17 \mathrm{eV})$ would also lead to a strong energy stabilization ( of $\sim 0.9 \mathrm{eV}$ ).

Once radical cation 14 is formed, a ring closure reaction can in principle take place to yield a radical cation 20 with a sixmembered ring (see Scheme 5). According to the DFT results, this scenario is not realistic, as the conversion from $\mathbf{1 4}$ to 20 is highly endergonic $(\Delta E=1.52 \mathrm{eV}$, from $-0.17 \mathrm{eV}$ for 14 to $+1.35 \mathrm{eV}$ for 20 ). The direct $\mathrm{C}-\mathrm{C}$ bond formation in $\mathbf{1 4}$ to form radical cation $\mathbf{1 8}$ is also unrealistic, because this structure is unstable and evolves back to the reactant 14 according to the DFT calculations. We rather invoke two other possible 
mechanisms displayed in Scheme 5. The first consists in a second oxidation reaction, giving rise to dication 19 prior to the ring closure. From 19, lying at $+0.74 \mathrm{eV}$ above the reactants, three possible scenarios can be envisioned, namely formation of either five- or six-membered ring, leading to dication $\mathbf{2 1}$ or 22, respectively, or reduction and protonation to yield arenium cation 17 followed by a $\mathrm{C}-\mathrm{C}$ bond formation to give arenium cation 23 with a five-membered ring. On the basis of energetics, we expect that $22(+1.36 \mathrm{eV})$ and $21(+1.66 \mathrm{eV})$ do not form, as this endergonic step requires large energy penalties (energy difference with respect to 19) of 0.62 and $0.92 \mathrm{eV}$, respectively. In contrast, the reduction and protonation of 19 and subsequent cyclization to produce arenium cation 23, lying at $+0.41 \mathrm{eV}$, is downhill, with an energy difference of $0.33 \mathrm{eV}$. The second mechanism involves the ring closure following the arenium cation mechanism. In fact, instead of obtaining dication 19 from radical cation 14 , it is possible to form arenium cation 17 , followed by the $\mathrm{C}-\mathrm{C}$ bond formation to yield arenium cation 23, through the arenium mechanism path (Scheme 5). From intermediate 23, the elimination of one proton leads to structure 24, lying at $-0.34 \mathrm{eV}$. Subsequent oxidation and deprotonation provide the aromatic semiproduct $25(-1.96 \mathrm{eV})$, and repetition of the same sequence finally yields product 2 .

Although the understanding of the complete reaction path of the Scholl reaction is still elusive, these calculations shed light onto two key aspects of this specific case. On the one hand, our calculations and control experiment suggest that the first reaction step (the aryl migration) likely takes place via a radical cation mechanism. On the other hand, based on energetics, it appears likely that the arenium ion mechanisms play an important role in the ring closure reaction to form 2. Further computational analyses are needed to understand the possible formation of a six-membered ring from the arenium mechanism, as well as to investigate the kinetic aspects of the reaction.

Notably, (R)-9b,14-bis(4-tert-butylphenyl)dibenzo[a,m]rubicen-5(9bH)-one (3) could also be isolated as a byproduct in $5 \%$ yield, upon the Scholl reaction of precursor 1a (Scheme 2). Characterization by MALDI-TOF MS, ${ }^{1} \mathrm{H}$ and ${ }^{13} \mathrm{C}$ NMR, and single-crystal $\mathrm{X}$-ray analyses unambiguously revealed the structure of $\mathbf{3}$ as shown in Figure 3a. Red crystals of $\mathbf{3}$ suitable for crystallographic analysis could be grown from solutions in
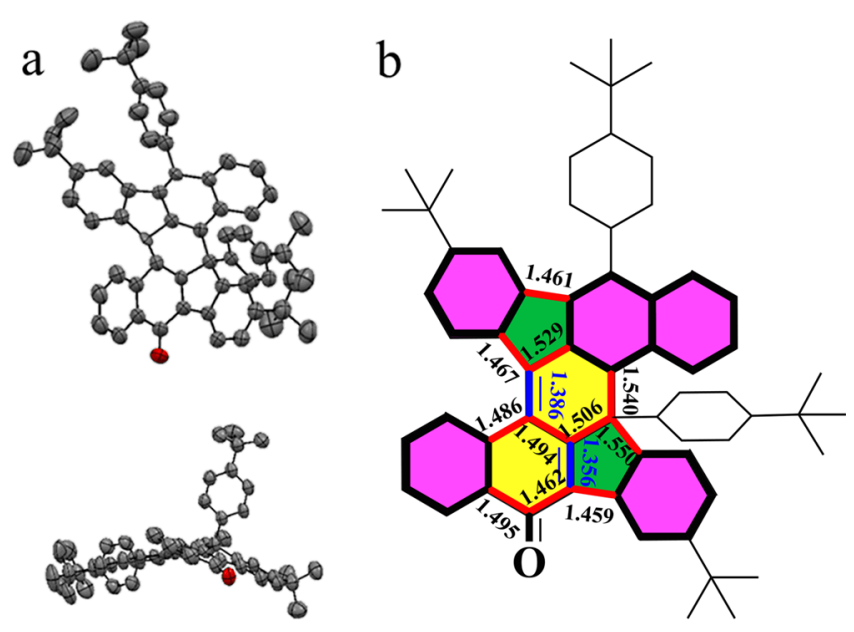

Figure 3. (a) Crystal structure of 3 (top and side views). (b) Bond lengths of 3 . hexane/dichloromethane. Similar to 2 , compound 3 also revealed a chiral structure due to the distorted carbon framework. The X-ray diffraction data disclose the detailed bond parameters of 3 (Figure $3 \mathrm{~b}$ ). The $\mathrm{C}-\mathrm{C}$ bonds within the five-membered rings are obviously longer $(1.46 \AA)$ than other bonds, and the central six-membered rings have short (blue) and long (red) bonds, which are identified as double and single bonds, respectively.

In order to block the 1,2-shift of aryl groups to the positions 5 and 12 in chrysene moiety of compound 1a, we examined the cyclodehydrogenation of $\mathbf{1 b}$ substituted with iodo groups. The Scholl reaction was, first, performed using $\mathrm{FeCl}_{3}$ as Lewis acid/ oxidant in dichloromethane. However, a mixture was obtained that could not be clearly identified through NMR and MALDITOF MS analyses. Therefore, a cyclodehydrogenation with DDQ and $\mathrm{CF}_{3} \mathrm{SO}_{3} \mathrm{H}$ was attempted. Surprisingly, an unexpected compound 4 with an eight membered ring was obtained in 33\% yield (Scheme 2). The chemical structure of 4 was confirmed by NMR, MALDI-TOF (Figure S1) and single crystal structure analysis (Figure 4). The formation of 4

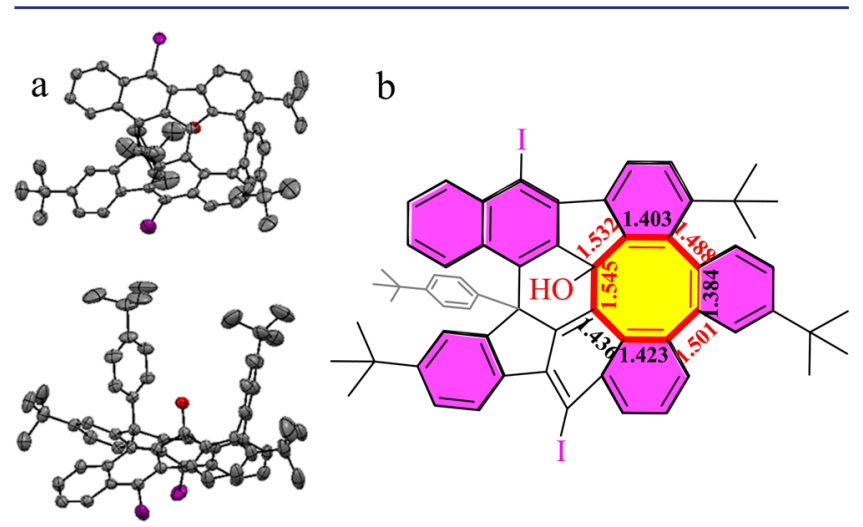

Figure 4. (a) Crystal structure of compound 4 (top and side views). (b) Bond lengths of 4 .

indicated that the blocking of the $\mathrm{C} 5$ and $\mathrm{C} 12$ could not force the formation of the six-membered rings, but rather induced the formation of five-membered rings with the very aryl groups that could not undergo the rearrangement. Moreover, rearrangement of another aryl group was suggested, forming an eightmembered ring. A possible mechanism for the formation of compound 4 through radical cation intermediates is shown in Supporting Information.

The UV-vis absorption spectra of precursor 1a and the cyclodehydrogenation products 2,3 and 4 in DCM solutions are compared in Figure 5a. The main absorption bands of 2, 3 and $\mathbf{4}$ are significantly red-shifted compared to that of precursor 1a, suggesting the extended conjugation. Compound 2 shows an absorption maximum at $508 \mathrm{~nm}$, while compound 3 exhibits a broad absorption band in the range of $465-618 \mathrm{~nm}$, as a result of the ketone formation. Similar to 3 , compound 4 also presents a broad absorption band in 470-600 nm. The optical energy gaps of 2, 3 and 4 are determined from the onsets of their UV-vis absorption spectra, which are 2.26, 1.96, and 1.94 $\mathrm{eV}$, respectively. Compounds $\mathbf{1 a}$ and $\mathbf{2}$ show fluorescence in DCM solution with maxima at 460 and $544 \mathrm{~nm}$ respectively (Figure 5b), while compounds 3 and 4 exhibit poor fluorescence. The electrochemical properties of 2, 3 and 4 were investigated by means of cyclic voltammetry $(\mathrm{CV})$ in DCM solutions (Figure S3). According to the CV analysis, 
Table 1. Optical and Electrochemical Properties of the 2, 3 and 4

\begin{tabular}{|c|c|c|c|c|c|c|c|c|c|}
\hline & $\lambda_{\max }{ }^{a}[\mathrm{~nm}]$ & $\lambda_{\mathrm{em}}{ }^{b}[\mathrm{~nm}]$ & $\lambda_{\text {edge }}[\mathrm{nm}]$ & $E_{\mathrm{g}, \mathrm{opt}}{ }^{c}[\mathrm{eV}]$ & $E_{\mathrm{HOMO}, \mathrm{CV}}{ }^{d}[\mathrm{eV}]$ & $E_{\mathrm{LUMO}, \mathrm{CV}}{ }^{e}[\mathrm{eV}]$ & $E_{\text {HOMO,cal }} f[\mathrm{eV}]$ & $E_{\text {LUMO,cal }} f[\mathrm{eV}]$ & $E_{\mathrm{g}, \mathrm{cal}}[\mathrm{eV}]$ \\
\hline 1a & 391 & 460 & 430 & 2.89 & - & - & -5.02 & -1.57 & 3.45 \\
\hline 2 & 508 & 544 & 549 & 2.26 & -5.77 & -3.54 & -5.06 & -2.11 & 2.95 \\
\hline 3 & 550 & - & 634 & 1.96 & -5.69 & -3.79 & -5.16 & -2.76 & 2.40 \\
\hline 4 & 535 & - & 640 & 1.94 & -5.92 & -3.98 & -5.72 & -1.64 & 3.94 \\
\hline
\end{tabular}

${ }^{a} \lambda_{\max }$ : absorption maximum at longest wavelength. ${ }^{b} \lambda_{\mathrm{em}}$ : emission wavelength. ${ }^{c}$ Optical energy gaps were estimated from the wavelength of the onsets of their UV-vis absorption spectra. ${ }^{d} \mathrm{HOMO}$ values were derived from the first measured oxidation potential. ${ }^{e} \mathrm{LUMO}$ levels were calculated from the optical band gap Eg(opt) and the respective HOMO levels. ${ }^{f}$ Calculations were performed at the B3LYP/6-31G (d,p) level.
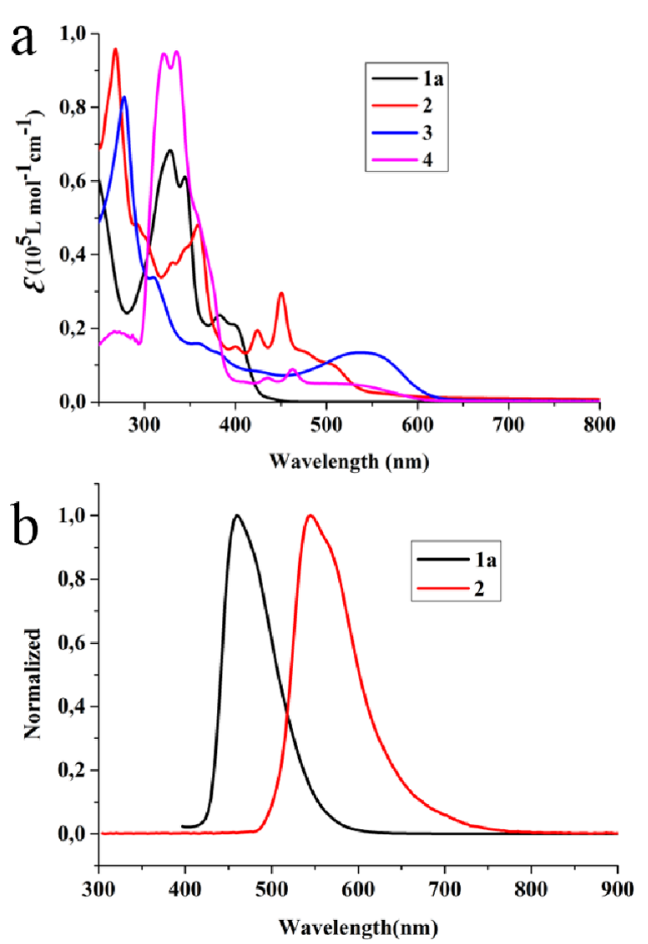

Figure 5. (a) UV-vis absorption spectra of 1 a, 2, 3 and 4. (b) Fluorescence spectra of $1 \mathrm{a}$ and 2 (for all spectra: $10^{-5} \mathrm{M}$ in DCM).

compound 2 exhibits one reversible oxidation and one reversible reduction process, whereas there are one reversible oxidation and two reversible reductions for 3 . In contrast, there is only one reversible reduction for 4. The HOMO energy levels estimated from the onsets of the reversible oxidation peaks are -5.77 and $-5.69 \mathrm{eV}$ for 2 and 3, respectively. Thus, the LUMO energy levels of these compounds are calculated based on their HOMO levels and optical gaps, as listed in Table 1. The results are fully consistent with the DFT calculations (see SI).

DFT calculations were further conducted to compare the electronic properties of the bistetracene analogue with fivemembered rings and the conventional bistetracene (Scheme 1), consisting solely of six-membered rings. The shape of the highest occupied molecular orbital (HOMO) and the lowest unoccupied molecular orbital (LUMO) are displayed in Figure 6. The HOMO of the conventional bistetracene is much higher than that of bistetracene analogue $\mathbf{2}$. Accordingly, $\mathbf{2}$ has a larger energy gap and is stable enough to allow its synthesis and easy handling, whereas the six-membered bistetracene possesses a prominent biradical character in the ground state and easily undergoes oxidation under ambient conditions. ${ }^{35}$

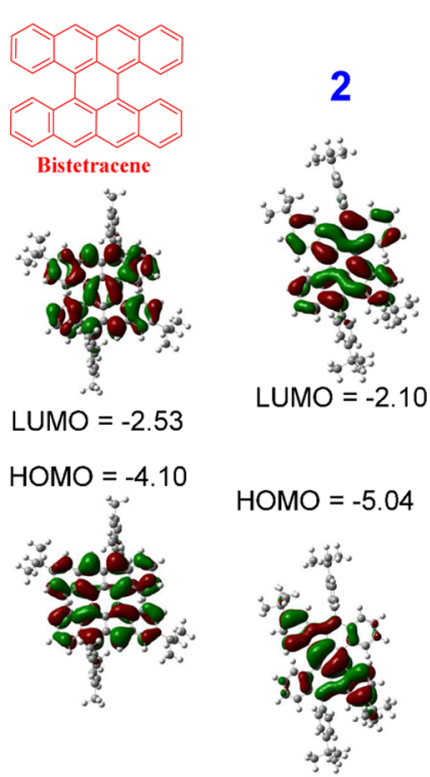

Figure 6. Shape of HOMOs and LUMOs of bistetracene and bistetracene analogue 2 . The calculations were performed with DFT B3LYP 6-31G $(\mathrm{d}, \mathrm{p})$ based on geometries derived from crystal structure data of 2 .

\section{CONCLUSION}

In summary, we have synthesized a stable bistetracene analogue with five-membered rings through the Scholl reaction of 6,7,13,14-tetraarylbenzo[ $k]$ tetraphene, which induced selective five-membered-ring formation after 1,2-shift of the aryl groups. A novel polycycle with five- and eight-membered ring was also obtained when the C5 and C12 positions were blocked with iodo groups. These compounds were investigated by UV-vis absorption spectroscopy, cyclic voltammetry, and single-crystal structure analysis, as well as by the DFT calculations. We found that the bistetracene analogue with five-membered rings is more stable compared to the conventional bistetracene consisting only of six-membered rings. Furthermore, a possible reaction mechanism for the formation of the bistetracene analogue was proposed, which could be clearly rationalized by theoretical studies. These results might pave the way toward the development of stable peri-tetracene- and peri-pentacene-like molecules, possibly incorporating five-, seven-, and/or eightmembered rings, by taming the otherwise uncontrollable side reactions during the Scholl reaction.

\section{ASSOCIATED CONTENT}

\section{Supporting Information}

The Supporting Information is available free of charge on the ACS Publications website at DOI: 10.1021/jacs.5b10399. 
Experimental details, NMR, MALDI-TOF MS, UV-vis spectra, cylic voltammograms, and computational details. (PDF)

Crystallographic data for $\mathbf{1 b}$. (CIF)

Crystallographic data for 2. (CIF)

Crystallographic data for 3 . (CIF)

Crystallographic data for 4. (CIF)

\section{AUTHOR INFORMATION}

\section{Corresponding Authors}

*xinliang.feng@tu-dresden.de

*muellen@mpip-mainz.mpg.de

Notes

The authors declare no competing financial interest.

\section{ACKNOWLEDGMENTS}

This work was financially supported by ERC grants on NANOGRAPH and 2DMATER, DFG Priority Program SPP 1459, EU Project GENIUS and MoQuaS, the EC under Graphene Flagship (No. CNECT-ICT-604391), and the Office of Naval Research BRC Program. D.B. is a FNRS Research Director.

\section{REFERENCES}

(1) Wu, J.; Pisula, W.; Müllen, K. Chem. Rev. 2007, 107, 718-747.

(2) Grzybowski, M.; Skonieczny, K.; Butenschön, H.; Gryko, D. T. Angew. Chem., Int. Ed. 2013, 52, 9900-9930.

(3) Narita, A.; Wang, X.-Y.; Feng, X.; Müllen, K. Chem. Soc. Rev. 2015, 44, 6616-6643.

(4) King, B. T.; Kroulík, J.; Robertson, C. R.; Rempala, P.; Hilton, C. L.; Korinek, J. D.; Gortari, L. M. J. Org. Chem. 2007, 72, 2279-2288.

(5) Scholl, R.; Mansfeld, J. Ber. Dtsch. Chem. Ges. 1910, 43, 17341746.

(6) Scholl, R.; Seer, C.; Weitzenböck, R. Ber. Dtsch. Chem. Ges. 1910, 43, 2202-2209.

(7) Stabel, A.; Herwig, P.; Müllen, K.; Rabe, J. P. Angew. Chem., Int. Ed. Engl. 1995, 34, 1609-1611.

(8) Schmidt-Mende, L.; Fechtenkötter, A.; Müllen, K.; Moons, E.; Friend, R. H.; MacKenzie, J. D. Science 2001, 293, 1119-1122.

(9) Jäckel, F.; Watson, M. D.; Müllen, K.; Rabe, J. P. Phys. Rev. Lett. 2004, 92, 188303.

(10) Dötz, F.; Brand, J. D.; Ito, S.; Gherghel, L.; Müllen, K. J. Am. Chem. Soc. 2000, 122, 7707-7717.

(11) Simpson, C. D.; Brand, J. D.; Berresheim, A. J.; Przybilla, L.; Rader, H. J.; Müllen, K. Chem. - Eur. J. 2002, 8, 1424-1429.

(12) Narita, A.; Feng, X.; Hernandez, Y.; Jensen, S. A.; Bonn, M.; Yang, H.; Verzhbitskiy, I. A.; Casiraghi, C.; Hansen, M. R.; Koch, A. H. R.; Fytas, G.; Ivasenko, O.; Li, B.; Mali, K. S.; Tatyana, B.; Mahesh, S.; Feyter, S. D.; Müllen, K. Nat. Chem. 2014, 6, 126-132.

(13) Kawasumi, K.; Zhang, Q.; Segawa, Y.; Scott, L. T.; Itami, K. Nat. Chem. 2013, 5, 739-744.

(14) Cheung, K. Y.; Xu, X.; Miao, Q. J. Am. Chem. Soc. 2015, 137, $3910-3914$

(15) Sakamoto, Y.; Suzuki, T. J. Am. Chem. Soc. 2013, 135, 1407414077.

(16) Schültter, F.; Nishiuchi, T.; Enkelmann, V.; Müllen, K. Angew. Chem., Int. Ed. 2014, 53, 1538-1542.

(17) Müller, M.; Mauermann-Düll, H.; Wagner, M.; Enkelmann, V.; Müllen, K. Angew. Chem., Int. Ed. Engl. 1995, 34, 1583-1586.

(18) Dou, X.; Yang, X.; Bodwell, G. J.; Wagner, M.; Enkelmann, V.; Müllen, K. Org. Lett. 2007, 9, 2485-2488.

(19) Balaban, A. T.; Nenitzescu, C. D. Friedel-Crafts and Related Reaction; Olah, G. A., Ed.; Wiley \& Sons: New York, 1964; Vol. 2, pp 979-1047.

(20) Iyer, V. S.; Yoshimura, K.; Enkelmann, V.; Epsch, R.; Rabe, J. P.; Müllen, K. Angew. Chem., Int. Ed. 1998, 37, 2696-2699.
(21) Dötz, F.; Brand, J. D.; Ito, S.; Gherghel, L.; Müllen, K. J. Am. Chem. Soc. 2000, 122, 7707-7717.

(22) Pradhan, A.; Dechambenoit, P.; Bock, H.; Durola, F. J. Org. Chem. 2013, 78, 2266-2274.

(23) Ajaz, A.; McLaughlin, E. C.; Skraba, S. L.; Thamatam, R.; Johnson, R. P. J. Org. Chem. 2012, 77, 9487-9495.

(24) Vingiello, F. A.; Youssef, A. K. Chem. Commun. 1968, 2, 68-69.

(25) Vingiello, F. A.; Yanez, J.; Campbell, J. A. J. Org. Chem. 1971, 36, 2053-2056.

(26) Avlasevich, Y.; Kohl, C.; Müllen, K. J. Mater. Chem. 2006, 16, $1053-1057$.

(27) Nagarajan, S.; Barthes, C.; Girdhar, N. K.; Dang, T. T.; Gourdon, A. Tetrahedron 2012, 68, 9371-9375.

(28) Markoulides, M. S.; Venturini, C.; Neumeyer, D.; Gourdon, A. New J. Chem. 2015, 39, 6498-6503.

(29) Skraba-Joiner, S. L.; McLaughlin, E. C.; Ajaz, A.; Thamatam, R.; Johnson, R. P. J. Org. Chem. 2015, 80, 9578-9583.

(30) Hepp, A.; Heil, H.; Weise, W.; Ahles, M.; Schmechel, R.; Seggern, H. Phys. Rev. Lett. 2003, 91, 157406.

(31) Giri, G.; Verploegen, E.; Mannsfeld, S. C. B.; Atahan-Evrenk, S.; Kim, D. H.; Lee, S. Y.; Becerril, H. A.; Aspuru-Guzik, A.; Toney, M. F.; Bao, Z. Nature 2011, 480, 504-508.

(32) Watanabe, M.; Chen, K.-Y.; Chang, Y. J.; Chow, T. J. Acc. Chem. Res. 2013, 46, 1606-1615.

(33) Walker, B. J.; Musser, A. J.; Beljonne, D.; Friend, R. H. Nat. Chem. 2013, 5, 1019-1024.

(34) Anthony, J. E. Angew. Chem., Int. Ed. 2008, 47, 452-483.

(35) Liu, J.; Ravat, P.; Wagner, M.; Baumgarten, M.; Müllen, K. Angew. Chem., Int. Ed. 2015, 54, 12442-12446.

(36) Chase, D. T.; Fix, A. G.; Rose, B. D.; Weber, C. D.; Nobusue, S.; Stockwell, C. E.; Zakharov, L. N.; Lonergan, M. C.; Haley, M. M. Angew. Chem., Int. Ed. 2011, 50, 11103-11106.

(37) Chase, D. T.; Rose, B. D.; McClintock, S. P.; Zakharov, L. N.; Haley, M. M. Angew. Chem., Int. Ed. 2011, 50, 1127-1130.

(38) Stephens, P. J.; Devlin, F. J.; Chabalowski, C. F.; Frisch, M. J. J. Phys. Chem. 1994, 98, 11623-11627.

(39) Rassolov, V. A.; Ratner, M. A. J.; Pople, A.; Redfern, P. C.; Curtiss, L. A. J. Comput. Chem. 2001, 22, 976-984.

(40) Stefano, M.; Negri, F.; Carbone, P.; Müllen, K. Chem. Phys. 2005, 314, 85-99.

(41) Rempala, P.; Kroulík, J.; King, B. T. J. Org. Chem. 2006, 71, 5067-5081.

(42) Ronlan, A.; Hammerich, O.; Parker, V. D. J. Am. Chem. Soc. 1973, 95, 7132-7138

(43) Rathore, R.; Kochi, J. K. J. Org. Chem. 1995, 60, 7479-7490.

(44) Stephens, Z. J.; Devlin, F. J.; Chabalowski, C. F.; Frisch, M. J. J. Phys. Chem. 1994, 98, 11623-11627.

(45) Rassolov, V. A.; Ratner, M. A.; Pople, J. A.; Redfern, P. C.; Curtiss, L. A. J. Comput. Chem. 2001, 22, 976-984.

(46) Frisch, M. J.; Trucks, G. W.; Schlegel, H. B.; Scuseria, G. E.; Robb,M. A.; Cheeseman, J. R.; Scalmani, G.; Barone, V.; Mennucci, B.; Petersson, G. A.; Nakatsuji, H.; Caricato, M.; Li, X.; Hratchian, H. P.; Izmaylov, A. F.; Bloino, J.; Zheng, G.; Sonnenberg, J. L.; Hada, M.; Ehara, M.; Toyota, K.; Fukuda, R.; Hasegawa, J.; Ishida, M.; Nakajima, T.; Honda, Y.; Kitao, O.; Nakai, H.; Vreven, T.; Montgomery, Jr., J. A.; Peralta, J. E.; Ogliaro, F.; Bearpark, M.; Heyd, J. J.; Brothers, E.; Kudin, K. N.; Staroverov, V. N.; Kobayashi, R.; Normand, J.; Raghavachari, K.; Rendell, A.; Burant, J. C.; Iyengar, S. S.; Tomasi, J.; Cossi, M.; Rega, N.; Millam, J. M.; Klene, M.; Knox, J. E.; Cross, J. B.; Bakken, V.; Adamo, C.; Jaramillo, J.; Gomperts, R.; Stratmann, R. E.; Yazyev, O.; Austin, A. J.; Cammi, R.; Pomelli, C.; Ochterski, J. W.; Martin, R. L.; Morokuma, K.; Zakrzewski, V. G.; Voth, G. A.; Salvador, P.; Dannenberg, J. J.; Dapprich, S.; Daniels, A. D.; Farkas, O.; Foresman, J. B.; Ortiz, J. V.; Cioslowski, J.; Fox, D. J. Gaussian 09, Revision A.1; Gaussian, Inc.: Wallingford, CT, 2009.

(47) Zhai, L.; Shukla, R.; Wadumethrige, S. H.; Rathore, R. J. Org. Chem. 2010, 75, 4748-4760. 